\title{
Self-Perception and General Perception of the Safety Impact of Autonomous Vehicles on Pedestrians, Bicyclists, and People with Ambulatory Disability
}

\author{
Devajyoti Deka*, Charles T. Brown \\ Alan M. Voorhees Transportation Center, Rutgers, The State University of New Jersey, New Brunswick, NJ, USA \\ Email:*ddeka@ejb.rutgers.edu, charles.brown@ejb.rutgers.edu
}

How to cite this paper: Deka, D. and Brown, C.T. (2021) Self-Perception and General Perception of the Safety Impact of Autonomous Vehicles on Pedestrians, Bicyclists, and People with Ambulatory Disability. Journal of Transportation Technologies, 11, 357-377.

https://doi.org/10.4236/jtts.2021.113023

Received: May 25, 2021

Accepted: June 19, 2021

Published: June 22, 2021

Copyright $\odot 2021$ by author(s) and Scientific Research Publishing Inc. This work is licensed under the Creative Commons Attribution International License (CC BY 4.0).

http://creativecommons.org/licenses/by/4.0/

\begin{abstract}
For autonomous vehicles (AVs) to receive general acceptance, society must have a positive perception about their safety impact on vulnerable road users. Using data from a statewide random-digit-dialing telephone survey of 1001 adults, this paper examines how New Jersey residents perceive the safety impact of AVs on pedestrians, bicyclists, and people with ambulatory disability. It uses a combination of confirmatory factor analysis and ordered probit models. Confirmatory factor analysis is used to create latent variables on socioeconomic status and built environment. Three ordered probit models are used to examine people's perception of AV safety impact on each of the three population groups. The models also examine how frequent walkers, bicyclists, and people with ambulatory disability perceive their own safety as well as the safety of the other two groups. All three models examine the effect of familiarity with $\mathrm{AV}$, gender, age, income, education, race, ethnicity, number of vehicles in household, political party affiliation, as well as built environment and socioeconomic status of the municipalities where the survey respondents live. The analysis showed that men, people with familiarity with the AV concept, Democrats, bicyclists, and people with high household income generally have a positive perception about the safety impact of AVs. While frequent walkers are ambivalent about their own safety as pedestrians, bicyclists have a positive perception about their own safety and the safety of pedestrians, whereas people with ambulatory disability have a strong negative perception about their own safety. The models did not show statistically significant effects of socioeconomic status or built environment of municipalities on AV safety perception.
\end{abstract}




\section{Keywords}

Safety Perception, Autonomous Vehicles, Pedestrian, Bicyclist, Disability

\section{Introduction}

The evolution of autonomous vehicles (AVs) has been rapid since the turn of the century, which began with the advanced driver assistance system (ADAS), characterized by Level-1 technologies that assist human drivers with steering and braking or accelerating functions [1]. With Level-2 technologies, vehicles have been able to control both steering and braking or accelerating under specific circumstances. Research and development with automated driving system (ADS), consisting of Level-3 through Level-5 technologies, are currently making significant progress. While advanced driver-assist features, rearview video systems, automatic emergency braking, pedestrian automatic emergency braking, rear automatic emergency braking, rear cross-traffic alert, lane centering assist, etc., are already available, partially automated safety features, lane-keeping features, adaptive cruise control, traffic jam assist, and self-park technologies are expected to improve further until 2025, when fully automated safety features are expected to be available for the public [1] [2]. With Level-4 technologies, a human driver is expected to be partially redundant, while with Level-5 technologies, human drivers are expected to be completely redundant as vehicles will be able to drive on their own in all circumstances.

The benefits from AVs are expected to be manifold: safety benefits, economic benefits, environmental benefits, and societal benefits. Regarding safety benefits, a study ([2], p. 2) maintains, "By eliminating the possibility of human error or poor human choices (e.g., impairment or distraction) while driving, ADS has enormous potential to save lives and reduce the economic burden associated with crashes." Transportation efficiency, equity, and convenience are all expected to increase with the evolution of AVs. Regarding benefits to people with disabilities, it maintains that "AVs hold enormous potential to promote the independence, economic opportunities, and social well-being of older Americans and persons with disabilities by offering independent mobility for daily activities" ([2], p. 3). Some authors have expressed the optimism that shared AVs will tremendously help to address one of the most pressing issues of our time: climate change [3].

However, for AVs to be accepted by society at large, potential AV users, nonusers, and government agencies will have to be convinced that the AV technology is safe for all roadway users. Many studies have been published so far inquiring about the safety perception of AVs, but given the novelty of the technology and the lack of experience of most people being on a driverless vehicle, or even interacting with a driverless vehicle on roadway, there is much to be learned about the perception of different types of roadway users. This paper adds 
to the existing body of literature on safety perception of AVs by focusing on three groups of vulnerable roadway users: pedestrians, bicyclists, and people with ambulatory disability. In contrast to most past studies that investigated how society at large perceives AV safety for vulnerable road users, this research compares how pedestrians, bicyclists, and people with ambulatory disability perceive AV safety for themselves as well as the other two groups. Given the importance of politics in the United States (US) regarding transportation infrastructure and technologies, this research also examines if AV safety perception varies by people's political party affiliation. In addition, it examines if familiarity with the $\mathrm{AV}$ concept and the characteristics of people's residential location affect the perception of AV safety. Regarding residential location, it considers both socioeconomic characteristics and built-environment characteristics.

This research is based on a statewide random-digit-dialing telephone (RDD) survey of 1001 adults living in New Jersey, a state located in the Atlantic coast of the US. New Jersey provides a unique opportunity for the research because it is both spatially and socio-demographically diverse. Some of its 21 counties and 565 municipalities are predominantly urban, some are suburban, and yet others are rural in nature. Although the state's median household income is one of the highest in the nation, the state is also home to many medium- and low-income residents. Some efforts are underway in the state to establish test beds for autonomous vehicles, but unlike some other parts of the country, there have not been any well-publicized efforts by private companies or government agencies to introduce driverless vehicles to the general public.

This paper's contributions are meaningful for several reasons. First, it examined the perception of AV safety impact for the survey sample by categorizing it into frequent walkers, bicyclists, people with ambulatory disability, and others. That allowed the comparison of self-perception about safety for the three vulnerable population groups with the perception of others. Second, the authors collected statewide data on people's perception of AV safety. Although many studies have been published that used data from specific cities, the use of statewide data in the given context is rare. Third, it compiled secondary data from a large number of sources to examine the potential effect of residential locations on the perception of AV safety. As discussed in the literature review, research on the impact of geographic location on AV safety perception has been rare despite the suggestion in studies that the impact of AVs will be felt differently in different environments.

\section{Relevant Literature}

A large number of studies have been published in recent years about the potential adoption of AVs in the US and other countries [4]-[14]. These studies indicate that AV adoption will depend on the acceptance by potential AV users as well the approval of society at large because a large number of non-users will share roads with AVs. Diverse factors may be important for potential AV users. 
While some studies [9] [15] have emphasized the importance of the level of control a driver has over the vehicle, others [16] [17] have emphasized the vehicle's ability to flawlessly navigate and maneuver on its own. Although it has been predicted by some [2] that AVs will be safer because they will eliminate human error, for AV non-users, especially vulnerable road users like pedestrians, bicyclists, and people with disabilities, having to share roads with vehicles with unfamiliar or vaguely familiar technologies can be a reason for extreme safety concern.

Research shows that being safe from AVs could be a legitimate concern for vulnerable road users even if they have reasonable knowledge about AV technologies [18] [19]. That is because AVs have the potential to make perception errors (i.e., errors in perceiving the environment), decision errors (i.e., errors in interpreting acquired information), and action errors (i.e., controlling the vehicle, such as accelerating, braking, etc., based on acquired information) [19]. A reason for concern among transportation agencies and researchers is that vulnerable road users themselves often behave erratically or unpredictably when using roadways [20]. It has also been suggested by researchers that instead of looking for cues from an AV, pedestrians may look for cues from AV passengers because of the acquired habit of receiving cues from non-AV drivers [21]. Social acceptance of AVs will ultimately depend on whether pedestrians will actually trust fully automated vehicles when they begin to replace the current generation of vehicles [22] [23]. Similar to pedestrian-AV interaction, a number of studies have addressed the interaction between bicyclists and AVs [17] [24]-[31]. Other studies often considered both pedestrians and bicyclists together as vulnerable road users in the context of AV safety [32]-[37]. More often than not, the focus of bicycling-related studies has been on various types of technologies rather than the perception of bicyclists.

The third group of people the current study focuses on, namely, people with disabilities, has also attained substantial attention from researchers in the context of AVs [2] [38] [39] [40] [41]. The mobility disadvantages of people with disabilities have also been addressed by studies on AVs for older adults [9] [42] [43]. While most literature on pedestrians and bicyclists is about the potential conflict of the two vulnerable groups of road users with AVs, most literature on people with disabilities, including the aforementioned studies, tends to focus on people with disabilities as AV riders. While people with disabilities may benefit as AV riders, they may also have to deal with conflicts with AVs when they share roads with AVs as pedestrians or wheelchair/scooter users.

An important issue this paper seeks to address is the effect of familiarity with AV on the perception of AV. Obviously, familiarity with AV can mean different things to different people at the present time because people can familiarize themselves by conducting online searches, reading newspapers, reading reports and academic publications, watching TV, driving vehicles with some advanced features, or interacting with AVs on the roadway in selected places where AVs have been tested. A study for Pittsburgh, where Uber tested 20 AVs, found that 
both pedestrians and bicyclists who interacted with AVs were slightly more likely to believe that AVs would reduce chances of fatalities and injuries compared to those who did not interact [36]. Another study [6] also found that people with prior knowledge of AVs have less concern about AV safety and adoption. A review of a large number of $\mathrm{AV}$ studies also concluded that prior knowledge about $\mathrm{AVs}$ is an important factor affecting people's perception of AVs, but whether an individual has a positive or negative perception depends on whether the prior knowledge is about positive or negative aspects of AVs [44].

Another issue this paper seeks to examine is the effect of place characteristics on the safety perception of AVs. Although one can infer from past studies [26] [44] [45] [46] that place characteristics may affect how people perceive AVs, only one study [47] was found that empirically examined the effect of residential location characteristics on the perception of AV safety and concluded that residents of pedestrian-friendly areas are more concerned about AVs, whereas residents living in areas with separated bicycling facilities are less concerned about AVs.

Of interest to this paper is also the effect of political ideology on the safety perception of AVs. Although no past study was found that directly examined the relationship between political party affiliation and AV safety perception, it can be inferred from past publications that Democrats or liberals could view AVs more favorably than Republicans or conservatives. This inference is partially rooted in researchers' expectation that AVs will address climate change, about which Republicans and conservatives have shown much greater skepticism than Democrats and liberals [3] [48]. Another reason is that past studies have found greater support for electric vehicles among Democrats than Republicans [49]. Yet another reason is that Republicans are more often opposed to new transportation infrastructure than Democrats because of the perception that infrastructure investment involves tax increases [50]. Although AV literature has paid only limited attention to public investments, safe operation of AVs will require substantial investment in road-side equipment [51].

Finally, this study is also interested in examining the effect of people's demographic and socioeconomic characteristics on the perception of AVs. From past research [6] [52], one can expect to see less concern about AV safety from men and younger people compared to women and older people. Based on an extensive review, one study [44] concluded that people with higher income and education have more favorable views of AVs, younger people are less concerned about AV safety, and people with disabilities are more enthusiastic about AVs compared to others. However, other research [47] found that people with high educational attainment and people who walk frequently are more concerned about AV safety than others.

\section{Primary and Secondary Data}

\subsection{The Survey of New Jersey Residents}

The primary data source for this research is a RDD survey of New Jersey adults 
aged 18 and over. The survey was conducted between October 18 and 24 of 2020 by trained professionals from a survey research center at the authors' institution. The survey questionnaire was approved by the institutional review board of the authors' institution. A total of 1001 persons responded to the survey, of which 400 were contacted by landline phone and 601 were contacted by cell phone. The respondent within each household was selected by asking randomly for the available youngest adult male or female. When a person of the identified gender was not available, the youngest adult of the other gender was interviewed. Depending on each respondent's choice of language, the survey was conducted in English or Spanish. The overall margin of error for the survey was $\pm 3.8 \%$ at $95 \%$ confidence level. The geographic distribution of the survey respondents was highly proportional to the share of adult population in New Jersey's 21 counties, as indicated by a very high correlation between sample size and population size $(\mathrm{r}=0.94, \mathrm{p}<0.001)$.

A few remarks are necessary to describe the important survey questions. The most important of them all, from which the dependent variables of the probit models were derived, was the question on traffic safety perception of autonomous vehicles. The exact language for the question was, "Please tell me if you think self-driving vehicles will increase traffic safety, decrease traffic safety, or not make much of a difference to traffic safety in New Jersey for each of the following groups?" followed by the mention of pedestrians, bicyclists, and people with disability. People with disability in the question was defined as "those who are disabled and/or use a mobility device or aid," meaning that the emphasis was on ambulatory disability. The term "self-driving vehicles" was used in the survey question to indicate that the question was about fully automated vehicles instead of the current generation of vehicles with advanced driver assistance systems.

The survey question on familiarity with autonomous vehicles had four response categories: Very familiar, somewhat familiar, not very familiar, and not at all familiar. The first two categories were combined into the category "familiar" and the last two categories were combined into the category "not familiar" of a binary variable. Finally, to identify the survey respondents with ambulatory disability, instead of asking if they had an ambulatory disability, they were asked if they used any mobility device, with specific mentions of cane, crutch, walker, wheelchair, and electric scooter. Based on the responses, $7.6 \%$ of all respondents were found to have an ambulatory disability, compared to $7 \%$ for the state shown by the 2018 American Community Survey (ACS). The demographic and socioeconomic characteristics of the survey respondents are shown in Table 1.

\subsection{Secondary Data}

To examine if the characteristics of residential locations have any effect on the safety perception of AVs, secondary data were combined from a number of sources for all of New Jersey's 565 municipalities. Because the survey only identified the respondents by zip code, the municipality names and codes were obtained by 
merging GIS layers of zip codes and municipalities. Data on demographic and socioeconomic characteristics were obtained from the 2018 ACS. Data pertaining to 2019 violent crime incidents in New Jersey municipalities were obtained from the FBI's website [53]. New Jersey's municipal level walk scores were obtained Table 1. Demographic and socioeconomic characteristics of the survey respondents.

\begin{tabular}{|c|c|c|}
\hline Characteristics & No. of Respondents & Percent \\
\hline \multicolumn{3}{|l|}{ Sex } \\
\hline Female & 486 & 48.6 \\
\hline Male & 515 & 51.4 \\
\hline Total & 1001 & 100.0 \\
\hline \multicolumn{3}{|l|}{ Age } \\
\hline $18-34$ & 57 & 5.9 \\
\hline $25-34$ & 115 & 11.9 \\
\hline $35-44$ & 174 & 18.0 \\
\hline $45-54$ & 202 & 20.9 \\
\hline $55-64$ & 228 & 23.6 \\
\hline $65-74$ & 115 & 11.9 \\
\hline $75+$ & 76 & 7.9 \\
\hline Total & 967 & 100.0 \\
\hline \multicolumn{3}{|l|}{ Race/ethnicity } \\
\hline White & 681 & 69.8 \\
\hline Black & 105 & 10.8 \\
\hline Hispanic & 106 & 10.9 \\
\hline Other & 84 & 8.6 \\
\hline Total & 976 & 100.0 \\
\hline \multicolumn{3}{|l|}{ Education } \\
\hline High school or less & 160 & 16.1 \\
\hline Some college & 246 & 24.8 \\
\hline Bachelor's degree & 303 & 30.5 \\
\hline Post-graduate & 284 & 28.6 \\
\hline Total & 993 & 100.0 \\
\hline \multicolumn{3}{|l|}{ Household income } \\
\hline Less than $\$ 25,000$ & 72 & 8.0 \\
\hline$\$ 25,000$ to $\$ 49,999$ & 134 & 14.9 \\
\hline$\$ 50,000$ to $\$ 74,999$ & 135 & 15.0 \\
\hline$\$ 75,000$ to $\$ 99,999$ & 160 & 17.8 \\
\hline$\$ 100,000$ to $\$ 149,999$ & 185 & 20.6 \\
\hline$\$ 150,000$ or more & 212 & 23.6 \\
\hline Total & 898 & 100.0 \\
\hline
\end{tabular}


from Walk Score ${ }^{\circledR}$ website [54]. GIS data on bus stop location were combined from all major transit agencies serving New Jersey. GIS data on road intersections were obtained from the New Jersey Department of Transportation.

\section{Analysis and Results}

\subsection{Confirmatory Factor Analysis}

Confirmatory factor analysis (CFA) was used to create two municipality-level latent variables, or factors: built-environment $(\mathrm{BE})$ and socioeconomic status (SES). CFA is a method to statistically combine ordinary variables into a broader but abstract variable that contains elements of the ordinary variables. Individual values of the broader variable, or factor, contain factor scores for each observation. The BE and SES factors were generated by CFA so that they could be used as explanatory variables in the probit models to examine how BE and SES of municipalities affect the perception of AV safety of their residents. An advantage of using a factor as an explanatory variable instead of an ordinary variable is that factors are more holistic or comprehensive than the latter.

Because there may be more frequent conflicts between AVs and vulnerable road users in urban environments, it was expected that the perception of safety from AVs would be negative in areas with more urban BE. There was no particular expectation about the relationship between municipal SES and the perception of AV safety because 1) past research has shown mixed results about the effect of education despite showing a positive effect of income, and 2) studies have rarely examined the effects of race, ethnicity, unemployment, crime, etc., on AV safety perception.

The BE factor was created by combining these highly correlated variables at the municipal level: walk score, intersection density, proportion of walk trips to work, number of bus stops, proportion of single-family homes, and population density. The SES factor was created by combining unemployment rate, proportion of people aged 25 or over with less than high school diploma, proportion of nonwhite population, proportion of people living in poverty, violent crime incidents per 100,000 people, and median home value.

The results of the confirmatory factor analysis to create the BE factor are presented in Table 2, whereas the results of the analysis to create the SES factor are presented in Table 3. The CALIS procedure in SAS was used for estimation. The fit statistics provided at the bottom of each table satisfy or exceed the recommended standards [55]. The signs of the coefficients of the variables entering the $\mathrm{BE}$ factor (e.g., positive signs for walk score, intersection density, population density, etc., and negative sign for proportion of single-family detached homes) indicate that a higher value of the $\mathrm{BE}$ factor represents more urban $\mathrm{BE}$ for a municipality. The signs of the coefficients of the variables entering the SES factor (e.g., positive signs for unemployment rate, poverty rate, etc., and negative sign for median home value) indicate that a higher value of the factor represents lower SES. Thus, a significant negative coefficient of the BE factor in a model on 
safety perception would indicate that safety perception is negative in more urban municipalities, whereas a negative coefficient for the SES factor would indicate a positive perception in municipalities with higher SES.

Table 2. Confirmatory factor analysis results estimating factor score for built environment.

\begin{tabular}{|c|c|c|c|c|c|}
\hline & Mean & Std. Dev. & Coeff. & t Value & $\mathrm{p}$ Value \\
\hline \multicolumn{6}{|l|}{ Variables } \\
\hline Walk score & 41.07 & 28.79 & 0.697 & 25.32 & $<0.0001$ \\
\hline Intersection density per acre & 0.28 & 0.72 & 0.173 & 3.82 & 0.0001 \\
\hline Percent walk trips to work & 2.39 & 3.01 & 0.517 & 14.48 & $<0.0001$ \\
\hline Number of one-way bus stops & 53.50 & 133.37 & 0.461 & 13.49 & $<0.0001$ \\
\hline Percent single family detached homes & 66.48 & 22.90 & -0.786 & -33.53 & $<0.0001$ \\
\hline Population density per square mile & 3482 & 5480 & 0.768 & 50.33 & $<0.0001$ \\
\hline \multicolumn{6}{|l|}{ Fit statistics } \\
\hline Goodness of Fit Index (GFI) & 0.994 & & & & \\
\hline Adjusted GFI (AGFI) & 0.986 & & & & \\
\hline Bentler Comparative Fit Index & 0.999 & & & & \\
\hline $\begin{array}{l}\text { Standardized Root Mean Square } \\
\text { Residual (SRMR) }\end{array}$ & 0.019 & & & & \\
\hline
\end{tabular}

Table 3. Confirmatory factor analysis results estimating factor score for socioeconomic status.

\begin{tabular}{|c|c|c|c|c|c|}
\hline & Mean & Std. Dev. & Coeff. & t Value & $\mathrm{p}$ Value \\
\hline \multicolumn{6}{|l|}{ Variables } \\
\hline Percent unemployed & 5.78 & 2.67 & 0.567 & 20.76 & $<0.0001$ \\
\hline $\begin{array}{l}\text { Percent with less education than high } \\
\text { school diploma }\end{array}$ & 8.06 & 6.10 & 0.823 & 48.74 & $<0.0001$ \\
\hline Percent non-white population & 20.40 & 17.34 & 0.568 & 18.47 & $<0.0001$ \\
\hline Percent population in poverty & 7.86 & 6.11 & 0.926 & 78.81 & $<0.0001$ \\
\hline Violent crime per 100,000 population & 112.09 & 171.32 & 0.767 & 51.09 & $<0.0001$ \\
\hline Median home value (\$) & 389,948 & 250,882 & -0.410 & -19.50 & $<0.0001$ \\
\hline \multicolumn{6}{|l|}{ Fit statistics } \\
\hline Goodness of Fit Index (GFI) & 0.943 & & & & \\
\hline Adjusted GFI (AGFI) & 0.868 & & & & \\
\hline Bentler Comparative Fit Index & 0.930 & & & & \\
\hline $\begin{array}{l}\text { Standardized Root Mean Square } \\
\text { Residual (SRMR) }\end{array}$ & 0.050 & & & & \\
\hline
\end{tabular}

\subsection{Ordered Probit Models on the Perception of AV Safety}

Three probit models were used to examine the effects of various explanatory variables on the perception of safety for pedestrians, bicyclists, and people with 
ambulatory disability. The QLIM procedure in SAS was used for estimation. The descriptive statistics for the variables used in the four models are presented in Table 4. The table shows the nature of the variables (e.g., categorical, continuous, etc.), the variable codes, as well as the arithmetic means and standard deviations. The three variables at the top of the table are the dependent variables for the ordered probit models shown in Table 5 . The mean for all three groups being close to 2 indicates an overall neutrality between increase in safety and decrease in safety because increase in safety was coded 3, safety remaining the same was coded 2, and decrease in safety was coded 1 . For all respondents combined, perceived safety for bicyclists is the lowest (1.97), followed by safety for pedestrians (2.01), and safety for people with ambulatory disability (2.14). Although the differences between the arithmetic means appear to be small, paired-sample t-tests showed that the difference between the mean for persons with disability is statistically different from the means for the other two groups at the $1 \%$ significance

Table 4. Descriptive statistics for the variables used in models.

\begin{tabular}{|c|c|c|}
\hline Variables & Mean & Std. Deviation \\
\hline Pedestrian safety $(1=$ decrease, $2=$ same, $3=$ increase $)$ & 2.008 & 0.876 \\
\hline Bicyclist safety $(1=$ decrease, $2=$ same, $3=$ increase $)$ & 1.971 & 0.876 \\
\hline People with disability safety $(1=$ decrease, $2=$ same, $3=$ increase $)$ & 2.137 & 0.874 \\
\hline Increase safety for pedestrians, bicyclists, and people with ambulatory disability (factor score, a continuous variable) & 0.013 & 0.738 \\
\hline Male $($ Male $=1$, Female $=0)$ & 0.541 & 0.499 \\
\hline Below age $45($ Yes $=1$, No $=0)$ & 0.368 & 0.483 \\
\hline Familiar with AV ( 1 = Familiar, 0 = Not familiar $)$ & 0.618 & 0.486 \\
\hline Frequent walker (Walks daily or almost daily $=1$, Walks less often or never $=0$ ) & 0.619 & 0.486 \\
\hline Bicyclist $($ Bicycles at least sometimes $=1$, Never bicycles $=0$ ) & 0.487 & 0.500 \\
\hline Has ambulatory disability $(\mathrm{Yes}=1, \mathrm{No}=0)$ & 0.084 & 0.277 \\
\hline Three or more vehicles in household $($ Yes $=1, \mathrm{No}=0$ ) & 0.258 & 0.438 \\
\hline No vehicles in household $($ Yes $=1$, No $=0)$ & 0.042 & 0.200 \\
\hline Income $\$ 150,000$ or higher $($ Yes $=1, \mathrm{No}=0)$ & 0.242 & 0.429 \\
\hline Income less than $\$ 50,000($ Yes $=1, \mathrm{No}=0)$ & 0.224 & 0.417 \\
\hline Has at least a bachelor's degree $(\mathrm{Yes}=1, \mathrm{No}=0)$ & 0.586 & 0.493 \\
\hline Hispanic $($ Yes $=1$, No $=0)$ & 0.107 & 0.310 \\
\hline White $(\mathrm{Yes}=1, \mathrm{No}=0)$ & 0.743 & 0.437 \\
\hline Democrat $($ Yes $=1$, No $=0)$ & 0.414 & 0.493 \\
\hline Republican $($ Yes $=1, \mathrm{No}=0)$ & 0.264 & 0.441 \\
\hline Socioeconomic status of residential area (factor score, a continuous variable) & 0.439 & 1.855 \\
\hline Built environment of residential area (factor score, a continuous variable) & 8.524 & 25.271 \\
\hline
\end{tabular}

Note: The mean and standard deviation shown may not exactly represent the variable sets used for each model in Table 5 because they were computed from observations that are common to all models. 
level and the mean for pedestrian safety is different from the mean for bicyclist safety at the $5 \%$ significance level. The remaining variables in the table are explanatory variables.

In the first model of Table 5, the dependent variable is perceived safety for pedestrians, in the second model, the dependent variable is perceived safety for bicyclists and in the third model, the dependent variable is perceived safety for

Table 5. Results of ordered probit models on the perception of pedestrian safety, bicyclist safety, and disabled safety from AVs.

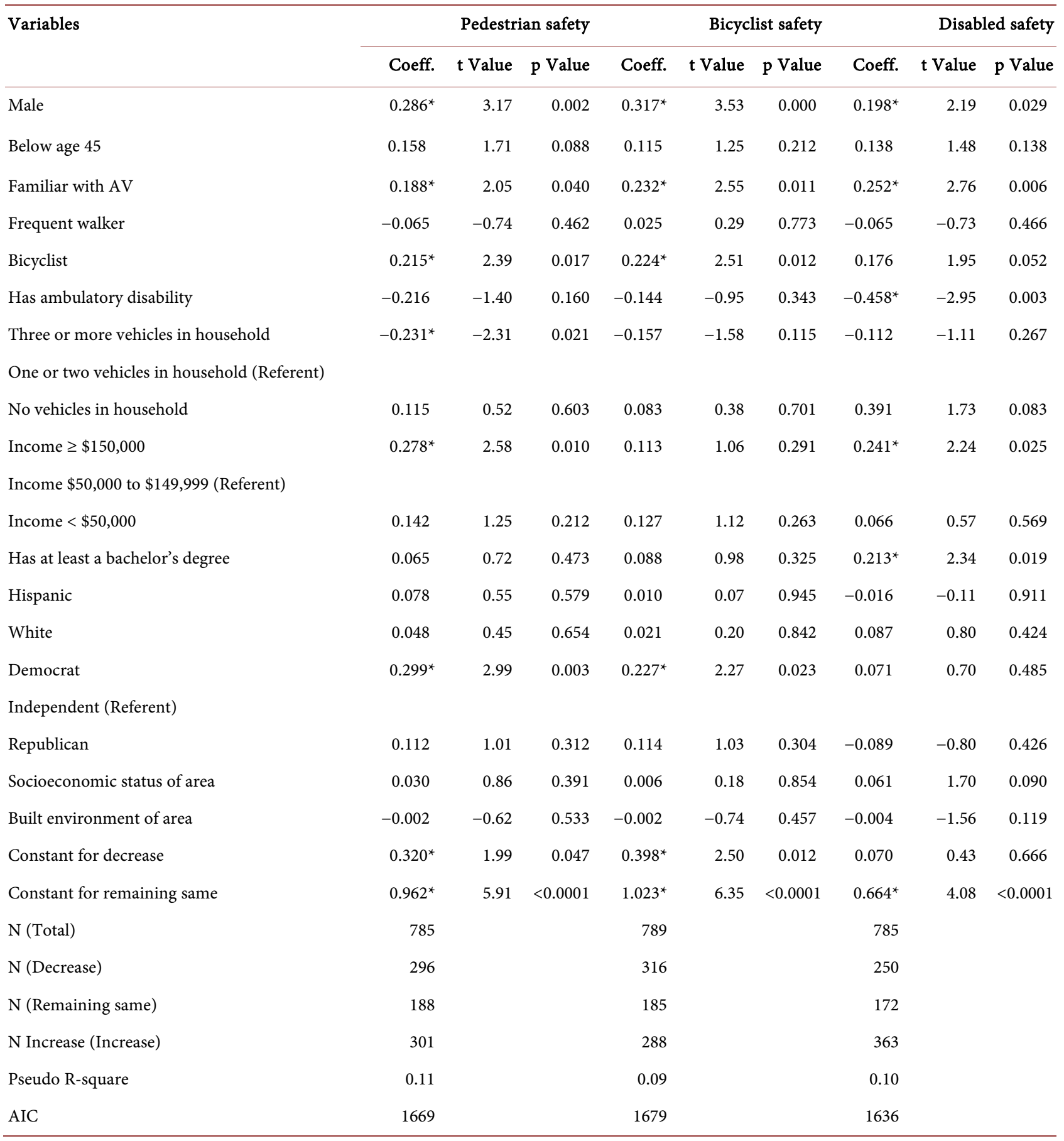

*Significant at $5 \%$ level. 
people with ambulatory disability. Because in all three cases, "decrease in safety" was coded 1, "remain the same" was coded 2, and "increase in safety" was coded 3 , the models predict increase in safety with intercepts for remaining the same and decrease safety.

In addition to showing the model-specific statistics at the bottom, Table 5 shows the coefficient, $\mathrm{t}$ value, and $\mathrm{p}$ value for each explanatory variable. The variables are significant at the $5 \%$ level when $\mathrm{p}<0.05$. In the model on perception of safety for pedestrians, six variables are statistically significant at that level. The model indicates that men, people who are familiar with the AV concept, bicyclists, people with household income of $\$ 150,000$ or higher, and Democrats are more likely to believe that AVs will increase safety for pedestrians. On the other hand, people who already have three or more vehicles in household are more likely to believe that AVs will decrease safety for pedestrians. The other variables are not statistically significant at the $5 \%$ level. The dummy variable on age below 45 is only significant at the $10 \%$ level, which is beyond the conventional standard of $5 \%$. Other variables, such as race, Hispanic ethnicity, higher education, socioeconomic status of the municipality, and the built environment of the municipality, are not statistically significant. One of the most notable observations from the model is that frequent walkers, i.e., people who walk daily or almost daily, are ambivalent or neutral about the impact of AVs on pedestrian safety. Although the sign of the coefficient is negative, the $\mathrm{p}$ value indicates that frequent walkers are split in their perception between increase and decrease of safety. People with ambulatory disability seem to be unsure about the safety for pedestrians as well. In contrast, bicyclists are more likely to believe that AVs will increase pedestrian safety compared to non-bicyclists.

While six variables were statistically significant at the $5 \%$ level in the model on safety for pedestrians, only four variables are significant at that level in the model on safety for bicyclists. That is because the variable on three or more vehicles in household and income $\$ 150,000$ or over are no longer significant in the bicyclist safety model despite retaining the same signs as the model on pedestrian safety. The most important distinction between the model on safety for pedestrians and the model on safety for bicyclists is that bicyclists themselves believe that AVs will increase their safety, whereas frequent walkers as a whole are unsure about the safety of pedestrians.

Five variables are significant at the $5 \%$ level in the model on safety for people with ambulatory disability. However, two of the variables that are significant in this model were not significant in the other two models. The first is the dummy variable representing people with ambulatory disability. The negative sign for the variable indicates that, compared to others, people with ambulatory disability are more likely to believe that AVs will decrease their own safety. This is a sharp contrast with bicyclists' perception about their own safety, shown by the previous model. The other significant variable is the one representing at least a bachelor's degree, the positive sign of the variable indicating that people with 
higher education are more likely to believe that AVs will increase safety for people with ambulatory disability. The variable representing bicyclists, which was significant in the two previous models at the $5 \%$ level, is significant in this model only at the $10 \%$ level $(\mathrm{p}=0.052)$. The variable on Democratic party affiliation, significant in the two previous models at the $5 \%$ level, is not significant in this model.

\subsection{Marginal Effects the Significant Variables}

Because of the complexity in directly interpreting the magnitude of the coefficients of ordered probit models, the marginal effects of the statistically significant variables from Table 5 are presented in Table 6 for simpler explanation of the model results. The three columns in the table are decrease safety, remain the same, and increase safety. The numbers are the marginal effects at the mean for each variable shown. A number in any column for a variable is the percentage point by which the stated population group represented by the variable differs from the comparison group. For instance, the number -0.103 for males in the first column indicates that, controlling for other variables, the likelihood of men selecting decrease in safety is 10.3 percentage points lower than women selecting that option. Similarly, from the column labeled increase safety, one can infer that the likelihood of men selecting increase safety is 10.4 percentage points greater than women selecting that option. By comparing the numbers within the model, one can see that being a Democrat makes the largest difference, followed by being male, and having a household income of $\$ 150,000$ or more, respectively.

A comparison of the numbers across the models shows that the effect of being male is slightly larger in the model for bicyclist safety compared to the model on pedestrian safety. Similarly, by comparing across the three models, one can see that the largest marginal effects are for people with ambulatory disability regarding their own safety from AVs. The results indicate that the likelihood of people with ambulatory disability believing that AVs will decrease their safety is 15.4 percentage points greater than others, whereas their likelihood of believing that AVs will increase their safety is 17.1 percentage points lower than others. These results indicate that the people with ambulatory disability are highly concerned about their own safety from AVs.

\section{Discussion}

The probit models showed that only a few of the variables expected to have a significant effect on the perception of AV safety impact are statistically significant at the $5 \%$ level. However, the models confirmed that the variables affecting the safety perception for the three population groups are not identical. The arithmetic means of the responses to the three questions showed that safety benefits are expected to be the most for people with ambulatory disability and the least for bicyclists. A reason for the overall perception that safety benefits to bicyclists will be the least is that bicycling is often considered to be unsafe by 
non-bicyclists. A reason for the overall perception that people with ambulatory disability will benefit the most may be that people often think about them as AV riders rather than ordinary roadway users interacting with AVs at intersections or crosswalks. The literature reviewed for this research [39] [40] [41] showed that more often than not, researchers have also considered people with disabilities as AV riders rather than pedestrians or wheelchair/scooter users interacting with AVs on roadways. The fact that the variable on higher education is significant (and positive) only in the model for people with disability seems to suggest that people with higher education are also more inclined to view AVs as a service-providing travel mode for people with disabilities. However, the people who have ambulatory disability may be more accustomed to thinking about themselves as pedestrians or wheelchair/scooter users rather than AV riders because the variable representing them is significant and negative in the model for people with disability despite not being significant in the other two models.

Table 6. Marginal effects of the statistically significant variables of the three models.

\begin{tabular}{|c|c|c|c|}
\hline Variables & \multicolumn{3}{|c|}{ Decrease safety Remain the same Increase safety } \\
\hline \multicolumn{4}{|l|}{ Model on safety perception for pedestrians } \\
\hline Male & -0.103 & -0.001 & 0.104 \\
\hline Familiar with AV & -0.067 & -0.001 & 0.068 \\
\hline Bicyclist & -0.077 & -0.001 & 0.078 \\
\hline Three or more vehicles in household & 0.083 & 0.001 & -0.084 \\
\hline Income $\$ 150,000$ or higher & -0.099 & -0.001 & 0.100 \\
\hline Democrat & -0.107 & -0.001 & 0.108 \\
\hline \multicolumn{4}{|l|}{ Model on safety perception for bicyclist } \\
\hline Male & -0.117 & 0.003 & 0.114 \\
\hline Familiar with AV & -0.085 & 0.002 & 0.083 \\
\hline Bicyclist & -0.082 & 0.002 & 0.081 \\
\hline Democrat & -0.083 & 0.002 & 0.082 \\
\hline \multicolumn{4}{|c|}{ Model on safety perception for people with disability } \\
\hline Male & -0.067 & -0.008 & 0.075 \\
\hline Familiar with AV & -0.085 & -0.010 & 0.095 \\
\hline Has ambulatory disability & 0.154 & 0.018 & -0.172 \\
\hline Income $\$ 150,000$ or higher & -0.081 & -0.010 & 0.091 \\
\hline Has at least a bachelor's degree & -0.072 & -0.008 & 0.080 \\
\hline
\end{tabular}

Consistent with previous studies [6] [36] [44], all models showed that familiarity with AV is positively associated with the perception that AVs will have a positive safety impact. The model results are also consistent with studies such as [6] and [52] in that they showed men having a more positive perception of AV safety impact than women. However, unlike those studies, this research found 
no relationship between people's age and the perception of AV safety impact. The variable used in the models (age below 45) is not significant at the $5 \%$ level in any of the four models despite being significant at the $10 \%$ level with the expected positive sign in the model on safety for pedestrians. Other variations of age, such as age below 35 , age 55 or over, and age 65 or over were also not found to be significant in any of the preliminary models tested, indicating that age is a questionable predictor of AV safety perception for New Jersey residents. Consistent with another study [44], this research also found evidence indicating that people with higher income are likely to have a more positive perception of AV safety impact than others.

Although a past study [47] found that frequent walkers are more concerned about a negative AV safety impact than others, this research found frequent walkers to be ambivalent about their own safety as well as the safety of bicyclists and people with disability. The past study [47] also found that people with higher education are more concerned about the safety impact of AVs, meaning that they could consider AVs as unsafe. While the variable on higher education was not significant in two of the three models in this research, it was significant with a positive sign in the model on safety for people with disability, indicating that people with higher education believe AVs will increase safety for this specific group.

One of the key findings of this research, that Democrats are more likely to have a positive perception of AV safety impact, is consistent with expectation, but close scrutiny of the model results showed that Democrats contrast more with Independents (the referent category) than Republicans. In two of the three models, the variable representing Republicans has a positive sign despite the variable not being statistically significant.

A population group that seems to have a very positive perception about the safety impact of AVs consists of bicyclists. In two of the three models, the variable representing bicyclists is significant and positive, and in the remaining model, it is almost significant at the $5 \%$ level $(\mathrm{p}=0.052)$. Because other studies have not included similar models to examine the perception of bicyclists about different vulnerable groups, one can only speculate why bicyclists could have such a positive perception. It is possible that having greater exposure to risky or unsafe roadway environments, bicyclists have higher safety perception than non-bicyclists. However, it is also possible that people with a positive traffic safety perception are more likely to bicycle than people with a negative safety perception.

In the probit model on safety impact of AVs on pedestrians, the dummy variable representing three or more vehicles in household was significant and negative, indicating that people with several vehicles in household have a negative perception about the safety impact of AVs on pedestrians. This could be considered a contradiction of expectation because 1) high-income people, who usually have more vehicles, have a positive perception about the safety impact of AVs, and 2) people with more vehicles in household should be more familiar with the AV concept and therefore they should have a positive perception about the im- 
pact of AVs. However, it is also possible that people who have more vehicles in household have more vehicles because they are more comfortable with the current, non-autonomous, vehicle technology, and therefore they do not have high expectations about the safety benefits of AVs.

Finally, the two variables relating to the municipalities of residence were not significant at the $5 \%$ level in any of the models, indicating that residential location characteristics do not have a discernible impact at the municipal level. Instead of providing generalizable evidence, these results suggest that more research is needed to understand the effects BE and SES on AV safety perception at different geographic levels.

\section{Conclusions}

This research showed that some of the variables that affect AV safety perception for the three population groups are identical, but others are different. Familiarity was found to have a positive effect on AV safety perception in all three models. Bicyclists, Democrats, and people with high income were also found to have a significant positive perception in two of the three models. These variables can be considered strong predictors of AV safety perception generally, whereas variables such as the number of household vehicles, level of education, and disability can be considered significant predictors for specific population groups only.

Despite answering some questions, this research also raises new questions. The first is about familiarity. Although familiarity with AV was found to be a strong predictor of AV safety perception, this research did not explain why some people have greater familiarity with $\mathrm{AV}$, given that $\mathrm{AVs}$ are not common in the study area at this time. It is possible that people who are inquisitive in nature and people who have a certain attitude toward new technologies are more familiar with the AV concept, but additional research is needed to explore such relationships. Given that this research did not find any evidence of residential location characteristics affecting AV safety perception, future studies should investigate if the scale of geographic areas matters when examining their effect on AV safety perception. Furthermore, given the strong negative perception of people with ambulatory disability about their own safety, additional research is needed to comprehend how people with ambulatory disability and other disabilities will interact with $\mathrm{AVs}$ as ordinary roadway users rather than $\mathrm{AV}$ riders.

Finally, because of data limitations, this research could not examine how people's perception of AV safety is affected by roadway traffic conditions in residential locations or neighborhoods. Nor could it examine the effect of proximity to motor vehicle crashes or crash hotspots. Future studies, especially those conducted at a smaller geographic scale, should consider including these variables as explanatory variables in statistical models.

\section{Acknowledgements}

This research was made possible by a grant from the New Jersey Department of 
Transportation and the Federal Highway Administration (Contract No. 19-38115). However, the agencies bear no liability for its content or use. The authors are solely responsible for any errors and omissions in the paper.

\section{Conflicts of Interest}

The authors declare no conflicts of interest regarding the publication of this paper.

\section{References}

[1] NHTSA (n.d.) Automated Vehicles for Safety. National Highway Traffic Safety Administration, Washington DC. https://www.nhtsa.gov/technology-innovation/automated-vehicles-safety

[2] NSTC and USDOT (2020) Ensuring American Leadership in Automated Vehicle Technologies: Automated Vehicles 4.0. National Science and Technology Council and the United States Department of Transportation, U.S. Department of Transportation, Washington DC.

[3] Sperling, D. (2018) Three Revolutions: Steering Automated, Shared, and Electric Vehicles to a Better Future. Island Press, Washington DC. https://doi.org/10.5822/978-1-61091-906-7

[4] Haboucha, C.J., Ishaq, R. and Shiftan, Y. (2017) User Preferences Regarding Autonomous Vehicles. Transportation Research Part C: Emerging Technologies, 78, 37-49. https://doi.org/10.1016/j.trc.2017.01.010

[5] Shariff, A., Bonnefon, J.F. and Rahwan, I. (2017) Psychological Roadblocks to the Adoption of Self-Driving Vehicles. Nature Human Behaviour, 1, 694-696.

https://doi.org/10.1038/s41562-017-0202-6

[6] Charness, N., Yoon, J.S., Souders, D., Stothart, C. and Yehnert, C. (2018) Predictors of Attitudes toward Autonomous Vehicles: The Roles of Age, Gender, Prior Knowledge, and Personality. Frontiers in Psychology, 9, 2589.

https://doi.org/10.3389/fpsyg.2018.02589

[7] Woldeamanuel, M. and Nguyen, D. (2018) Perceived Benefits and Concerns of Autonomous Vehicles: An Exploratory Study of Millennials' Sentiments of an Emerging Market. Research in Transportation Economics, 71, 44-53.

https://doi.org/10.1016/j.retrec.2018.06.006

[8] Acheampong, R.A. and Cugurullo, F. (2019) Capturing the Behavioural Determinants behind the Adoption of Autonomous Vehicles: Conceptual Frameworks and Measurement Models to Predict Public Transport, Sharing and Ownership Trends of Self-Driving Cars. Transportation Research Part F: Traffic Psychology and Behaviour, 62, 349-375. https://doi.org/10.1016/j.trf.2019.01.009

[9] Hassan, H.M., Ferguson, M.R., Razavi, S. and Vrkljan, B. (2019) Factors That Influence Older Canadians' Preferences for Using Autonomous Vehicle Technology: A Structural Equation Analysis. Transportation Research Record, 2673, 469-480. https://doi.org/10.1177/0361198118822281

[10] Montoro, L., Useche, S.A., Alonso, F., Lijarcio, I., Bosó-Seguí, P. and Martí-Belda, A. (2019) Perceived Safety and Attributed Value as Predictors of the Intention to Use Autonomous Vehicles: A National Study with Spanish Drivers. Safety Science, 120, 865-876. https://doi.org/10.1016/j.ssci.2019.07.041

[11] Asmussen, K.E., Mondal, A. and Bhat, C.R. (2020) A Socio-Technical Model of Au- 
tonomous Vehicle Adoption Using Ranked Choice Stated Preference Data. Transportation Research Part C: Emerging Technologies, 121, Article ID: 102835. https://doi.org/10.1016/j.trc.2020.102835

[12] Berrada, J., Mouhoubi, I. and Christoforou, Z. (2020) Factors of Successful Implementation and Diffusion of Services Based on Autonomous Vehicles: Users' Acceptance and Operators' Profitability. Research in Transportation Economics, 83, Article ID: 100902. https://doi.org/10.1016/j.retrec.2020.100902

[13] Koul, S. and Eydgahi, A. (2020) The Impact of Social Influence, Technophobia, and Perceived Safety on Autonomous Vehicle Technology Adoption. Periodica Polytechnica Transportation Engineering, 48, 133-142. https://doi.org/10.3311/PPtr.11332

[14] Raj, A., Kumar, J.A. and Bansal, P. (2020) A Multicriteria Decision Making Approach to Study Barriers to the Adoption of Autonomous Vehicles. Transportation Research Part A: Policy and Practice, 133, 122-137.

https://doi.org/10.1016/j.tra.2020.01.013

[15] Souka, M., Böger, D., Decker, R., Stummer, C. and Wiemann, A. (2020) Is More Automation Always Better? An Empirical Study of Customers' Willingness to Use Autonomous Vehicle Functions. International Journal of Automotive Technology and Management, 20, 1-24. https://doi.org/10.1504/IJATM.2020.105297

[16] Hancock, P.A. (2019) Some Pitfalls in the Promises of Automated and Autonomous Vehicles. Ergonomics, 62, 479-495. https://doi.org/10.1080/00140139.2018.1498136

[17] Thompson, J., Read, G.J., Wijnands, J.S. and Salmon, P.M. (2020) The Perils of Perfect Performance; Considering the Effects of Introducing Autonomous Vehicles on Rates of Car vs Cyclist Conflict. Ergonomics, 63, 981-996. https://doi.org/10.1080/00140139.2020.1739326

[18] Combs, T.S., Sandt, L.S., Clamann, M.P. and McDonald, N.C. (2019) Automated Vehicles and Pedestrian Safety: Exploring the Promise and Limits of Pedestrian Detection. American Journal of Preventive Medicine, 56, 1-7. https://doi.org/10.1016/j.amepre.2018.06.024

[19] Wang, J., Zhang, L., Huang, Y. and Zhao, J. (2020) Safety of Autonomous Vehicles. Journal of Advanced Transportation, 2020, Article ID: 8867757. https://doi.org/10.1155/2020/8867757

[20] Deb, S., Rahman, M.M., Strawderman, L.J. and Garrison, T.M. (2018) Pedestrians' Receptivity toward Fully Automated Vehicles: Research Review and Roadmap for Future Research. IEEE Transactions on Human-Machine Systems, 48, 279-290. https://doi.org/10.1109/THMS.2018.2799523

[21] Hudson, C.R., Deb, S., Carruth, D.W., McGinley, J. and Frey, D. (2019) Pedestrian Perception of Autonomous Vehicles with External Interacting Features. In: Nunes, I., Ed., Advances in Human Factors and Systems Interaction, AHFE 2018, Advances in Intelligent Systems and Computing, Vol. 781, Springer, Cham, 33-39.

https://doi.org/10.1007/978-3-319-94334-3_5

[22] Saleh, K., Hossny, M. and Nahavandi, S. (2017) Towards Trusted Autonomous Vehicles from Vulnerable Road Users Perspective. In: 2017 Annual IEEE International Systems Conference, IEEE, Piscataway, 1-7. https://doi.org/10.1109/SYSCON.2017.7934782

[23] Wang, K., Li, G., Chen, J., Long, Y., Chen, T., Chen, L. and Xia, Q. (2020) The Adaptability and Challenges of Autonomous Vehicles to Pedestrians in Urban China. Accident Analysis \& Prevention, 145, Article ID: 105692.

https://doi.org/10.1016/j.aap.2020.105692 
[24] Blau, M., Akar, G. and Nasar, J. (2018) Driverless Vehicles' Potential Influence on Bicyclist Facility Preferences. International Journal of Sustainable Transportation, 12, 665-674. https://doi.org/10.1080/15568318.2018.1425781

[25] Latham, A. and Nattrass, M. (2019) Autonomous Vehicles, Car-Dominated Environments, and Cycling: Using an Ethnography of Infrastructure to Reflect on the Prospects of a New Transportation Technology. Journal of Transport Geography, 81, Article ID: 102539. https://doi.org/10.1016/j.jtrangeo.2019.102539

[26] Saleh, K., Abobakr, A., Nahavandi, D., Iskander, J., Attia, M., Hossny, M. and Nahavandi, S. (2019) Cyclist Intent Prediction Using 3D Lidar Sensors for Fully Automated Vehicles. 2019 IEEE Intelligent Transportation Systems Conference (ITSC), Auckland, 27-30 October 2019, 2020-2026. https://doi.org/10.1109/ITSC.2019.8917291

[27] Tafidis, P., Pirdavani, A., Brijs, T. and Farah, H. (2019) Can Automated Vehicles Improve Cyclist Safety in Urban Areas? Safety, 5, 57.

https://doi.org/10.3390/safety5030057

[28] Hagenzieker, M.P., van der Kint, S., Vissers, L., van Schagen, I.N.G., de Bruin, J., van Gent, P. and Commandeur, J.J. (2020) Interactions between Cyclists and Automated Vehicles: Results of a Photo Experiment. Journal of Transportation Safety \& Security, 12, 94-115. https://doi.org/10.1080/19439962.2019.1591556

[29] Hou, M., Mahadevan, K., Somanath, S., Sharlin, E. and Oehlberg, L. (2020) Autonomous Vehicle-Cyclist Interaction: Peril and Promise. Proceedings of the 2020 CHI Conference on Human Factors in Computing Systems, Honolulu, 25-30 April 2020, 1-12. https://doi.org/10.1145/3313831.3376884

[30] Pettigrew, S., Nelson, J.D. and Norman, R. (2020) Autonomous Vehicles and Cycling: Policy Implications and Management Issues. Transportation Research Interdisciplinary Perspectives, 7, Article ID: 100188. https://doi.org/10.1016/j.trip.2020.100188

[31] von Sawitzky, T., Wintersberger, P., Löcken, A., Frison, A.K. and Riener, A. (2020) Augmentation Concepts with HUDs for Cyclists to Improve Road Safety in Shared Spaces. Extended Abstracts of the 2020 CHI Conference on Human Factors in Computing Systems, Honolulu, 25-30 April 2020, 1-9.

https://doi.org/10.1145/3334480.3383022

[32] Li, X., Li, L., Flohr, F., Wang, J., Xiong, H., Bernhard, M., Pan, S., Gavrila, D.M. and Li, K. (2016) A Unified Framework for Concurrent Pedestrian and Cyclist Detection. IEEE Transactions on Intelligent Transportation Systems, 18, 269-281. https://doi.org/10.1109/TITS.2016.2567418

[33] Lenard, J., Welsh, R. and Danton, R. (2018) Time-to-Collision Analysis of Pedestrian and Pedal-Cycle Accidents for the Development of Autonomous Emergency Braking Systems. Accident Analysis \& Prevention, 115, 128-136.

https://doi.org/10.1016/j.aap.2018.02.028

[34] Ahmed, S., Huda, M.N., Rajbhandari, S., Saha, C., Elshaw, M. and Kanarachos, S. (2019) Pedestrian and Cyclist Detection and Intent Estimation for Autonomous Vehicles: A Survey. Applied Sciences, 9, 2335. https://doi.org/10.3390/app9112335

[35] Botello, B., Buehler, R., Hankey, S., Mondschein, A. and Jiang, Z. (2019) Planning for Walking and Cycling in an Autonomous-Vehicle Future. Transportation Research Interdisciplinary Perspectives, 1, Article ID: 100012.

https://doi.org/10.1016/j.trip.2019.100012

[36] Penmetsa, P., Adanu, E.K., Wood, D., Wang, T. and Jones, S.L. (2019) Perceptions and Expectations of Autonomous Vehicles-A Snapshot of Vulnerable Road User 
Opinion. Technological Forecasting and Social Change, 143, 9-13. https://doi.org/10.1016/j.techfore.2019.02.010

[37] Pyrialakou, V.D., Gkartzonikas, C., Gatlin, J.D. and Gkritza, K. (2020) Perceptions of Safety on a Shared Road: Driving, Cycling, or Walking near an Autonomous Vehicle. Journal of Safety Research, 72, 249-258. https://doi.org/10.1016/j.jsr.2019.12.017

[38] USDOT (2018) Preparing for the Future of Transportation: Automated Vehicles 3.0. U.S. Department of Transportation, Washington DC.

[39] Bennett, R., Vijaygopal, R. and Kottasz, R. (2019) Attitudes towards Autonomous Vehicles among People with Physical Disabilities. Transportation Research Part A: Policy and Practice, 127, 1-17. https://doi.org/10.1016/j.tra.2019.07.002

[40] Bennett, R., Vijaygopal, R. and Kottasz, R. (2020) Willingness of People Who Are Blind to Accept Autonomous Vehicles: An Empirical Investigation. Transportation Research Part F: Traffic Psychology and Behaviour, 69, 13-27. https://doi.org/10.1016/j.trf.2019.12.012

[41] Hwang, J., Li, W., Stough, L., Lee, C. and Turnbull, K. (2020) A Focus Group Study on the Potential of Autonomous Vehicles as a Viable Transportation Option: Perspectives from People with Disabilities and Public Transit Agencies. Transportation Research Part F: Traffic Psychology and Behaviour, 70, 260-274. https://doi.org/10.1016/j.trf.2020.03.007

[42] Rahman, M.M., Deb, S., Strawderman, L., Burch, R. and Smith, B. (2019) How the Older Population Perceives Self-Driving Vehicles. Transportation Research Part F: Traffic Psychology and Behaviour, 65, 242-257.

https://doi.org/10.1016/j.trf.2019.08.002

[43] Kovacs, F.S., McLeod, S. and Curtis, C. (2020) Aged Mobility in the Era of Transportation Disruption: Will Autonomous Vehicles Address Impediments to the Mobility of Ageing Populations? Travel Behaviour and Society, 20, 122-132. https://doi.org/10.1016/j.tbs.2020.03.004

[44] Golbabaei, F., Yigitcanlar, T., Paz, A. and Bunker, J. (2020) Individual Predictors of Autonomous Vehicle Public Acceptance and Intention to Use: A Systematic Review of the Literature. Journal of Open Innovation: Technology, Market, and Complexity, 6, 106. https://doi.org/10.3390/joitmc6040106

[45] Millard-Ball, A. (2018) Pedestrians, Autonomous Vehicles, and Cities. Journal of Planning Education and Research, 38, 6-12. https://doi.org/10.1177/0739456X16675674

[46] Riggs, W., Appleyard, B. and Johnson, M. (2020) A Design Framework for Livable Streets in the Era of Autonomous Vehicles. Urban, Planning and Transport Research, 8, 125-137. https://doi.org/10.1080/21650020.2020.1749123

[47] Wang, K. and Akar, G. (2019) Effects of Neighborhood Environments on Perceived Risk of Self-Driving: Evidence from the 2015 and 2017 Puget Sound Travel Surveys. Transportation, 46, 2117-2136. https://doi.org/10.1007/s11116-019-10069-9

[48] Leiserowitz, A., Maibach, E., Rosenthal, S., Kotcher, J., Ballew, M., Bergquist, P., Gustafson, A., Goldberg, M. and Wang, X. (2020) Politics \& Global Warming. Yale University and George Mason University, Yale Program on Climate Change Communication, New Haven.

[49] Sintov, N.D., Abou-Ghalioum, V. and White, L.V. (2020) The Partisan Politics of Low-Carbon Transport: Why Democrats Are More Likely to Adopt Electric Vehicles than Republicans in the United States. Energy Research \& Social Science, 68, Article ID: 101576 . https://doi.org/10.1016/j.erss.2020.101576 
[50] Fogg, L.M., Hamilton, L.C. and Bell, E.S. (2020) Views of the Highway: Infrastructure Reality, Perceptions, and Politics. SAGE Open, 10. https://doi.org/10.1177/2158244020963609

[51] McGuckin, T., Lambert, J., Newton, D., Pearmine, A. and Hubbard, E. (2017) Leveraging the Promise of Connected and Autonomous Vehicles to Improve Integrated Corridor Management and Operations: A Primer. Federal Highway Administration, U.S. Department of Transportation, Washington DC.

[52] Hulse, L.M., Xie, H. and Galea, E.R. (2018) Perceptions of Autonomous Vehicles: Relationships with Road Users, Risk, Gender and Age. Safety Science, 102, 1-13. https://doi.org/10.1016/j.ssci.2017.10.001

[53] FBI (2019) New Jersey: Offences Known to Law Enforcement, by City. United States Department of Justice, Federal Bureau of Investigation, Washington DC.

https://ucr.fbi.gov/crime-in-the-u.s/2019/crime-in-the-u.s.-2019/tables/table-8/table -8-state-cuts/new_jersey.xls

[54] Walk Score (n.d.) Walk Score ${ }^{\circledR}$. https://www.walkscore.com/NJ

[55] Hooper, D., Coughlan, J. and Mullen, M.R. (2008) Structural Equation Modelling: Guidelines for Determining Model Fit. The Electronic Journal of Business Research Methods, 6, 53-60. 